\title{
Application of Taguchi and FEM to Explore the Surface Properties of Glass Using USM Process
}

\author{
Vinod Kumar* \\ Mechanical Engineering Department, Thapar University, Patiala, India \\ *Corresponding author: vsingla5@yahoo.com
}

Received September 25, 2013; Revised November 20, 2013; Accepted December 29, 2013

\begin{abstract}
The FEM analysis of ultrasonic tool has been done in addition to surface roughness of machined samples using ultrasonic machining process have been presented. The experimental conditions were designed by using DOE approach. The analysis of results has been done using the MINITAB 14.0 software and results obtained are validated by conducting the confirmation experiments. The F-test and P-value has been applied to determine the significant parameters.
\end{abstract}

Keywords: FEM, cracks, nodes, composition, roughness

Cite This Article: Vinod Kumar, "Application of Taguchi and FEM to Explore the Surface Properties of Glass Using USM Process." American Journal of Mechanical Engineering 2, no. 1 (2013): 1-7. doi: 10.12691/ajme-2-1-1.

\section{Introduction}

The improvement of machining quality can be vitally promoted through the conversion of this machining process into one involving controllable high frequency impacts at the cutting zone. This is achieved through the generation and maintenance of ultrasonic vibration in the cutting tool to alter the fracture process in brittle materials to one in which loading of the materials at the tip of tool, repetitive and under control. Engineering ceramic materials have many attractive properties such as high hardness, high thermal resistance, chemical stability and low electrical conductivity etc. Ceramic composites are assuming increasing industrial importance in machine building and engineering field, mainly because of the fact that technological limitation can be overcome by the use of these non-metallic materials. It is for this reason that ceramic composites have gained acceptance in a number of application imposing extreme demands on one or more properties of the material. Despite their outstanding properties as compared to metals, ceramic composites are only gradually gaining acceptance in mechanical engineering application. One reason for this is found to be in the limitation of the forming process which is done prior to sintering, which restricts the limitations of the forming process which is done prior to sintering, which restricts the generation of complex geometries and makes it difficult to ensure adequate accuracy and surface finish.

The optimum parameters for multi-performance characteristics in drilling using grey relational analysis were determined [1]. The design optimization of cutting parameters for side milling operations with multiple performance characteristics was done [2]. The statistical analysis of experimental parameters in ultrasonic machining of tungsten carbide using taguchi approach has been done [3]. The robust design of flank milling parameters based on grey-taguchi method was reported [4]. The effects of the Nd: YAG laser welding parameters on the bead formation on the neuro-stimulator were analysed by [5]. The effects of magnetic force on EDM machining characteristics were explored using $\mathrm{L}_{18}$ orthogonal array based on taguchi method and statistically evaluated the experimental data by analysis of variance (ANOVA). The MRR of magnetic force assisted EDM was almost three times as large as the value of standard EDM and the REWR was improved from $1.03 \%$ to $0.33 \%$ as determined [6]. The optimization of compensation cutting for eliminating the residual form error of an aspheric surface using the taguchi method was performed and the experimental trials based on the $\mathrm{L}_{9}(33)$ orthogonal array were carried out. Based on the results of analysis of variance, the most significant factor was compensation ratio having a percentage contribution of $49.37 \%$ as concluded by [7]. The refrigerants R22 and R404A five of their binary mixtures which contain about $0 \%, 25 \%, 50 \%$, $75 \%$ and $100 \%$ mass fractions of R404A were tested. The collected data were analyzed by using ANOVA. This work was done [8]. The influences of various surface treatments on indium-tin-oxide (ITO) anodes on the performance of OLED devices were investigated by applying the taguchi Method. The chemical treatment producing ultra-smooth ITO film surfaces does not provide the highest efficiency and luminescence as investigated by [9]. The contribution percentages of the rotational speed, feed, depth of cut, and pulsed frequency to the LBM performance was determined as $42.68 \%$, $22.58 \%, 20.73 \%$ and $14.01 \%$, respectively [10].

The experimental studies for WEDM were conducted under varying pulse duration, open circuit voltage, wire speed and dielectric flushing pressure. The settings of 
machining parameters were determined by using Taguchi experimental design method. The level of importance of the machining parameters on the cutting kerf and MRR was determined using analysis of variance (ANOVA) [11]. The implementation and selection of cutting path strategies with appropriate cutting parameters had significant effect on surface roughness as found by [12].

Reciprocating wear process parameters were optimized for minimum weight loss and friction based on mixed L16 Taguchi orthogonal design with three process parameters, sliding velocity, applied load and oil type. The experimental results were in good agreement with the values from the theoretical model. The optimal combination of parameters is found to be highest level of sliding velocity, lowest level of load and lowest level of oil type as determined [13]. Electro deposition of thin copper layer was carried out on titanium wires in acidic sulphate bath. The influence of titanium surface preparation, cathodic current density, copper sulphate and sulphuric acid concentrations, electrical charge density and stirring of the solution on the adhesion of the electrodeposits was studied using the taguchi statistical method [14]. The ANOVA results illustrated the influence of each V-ring indenter parameter on the smooth shear surface and cracks of the fine-blanked surface, together with their calculated percentage contributions as found [15].

A taguchi design investigation was made for the relationship between the micro porosity and process variables in a sand cast A360 aluminium alloy [16]. The effect of cutting speed, feed rate and drill point geometry on the residual tensile strength of the drilled unidirectional glass fibre reinforced epoxy composite were determined using the taguchi method [17]. The optimal setting of the process parameters on the electro-discharge machining (EDM) of carbon-carbon composites were determined using experiments planned, conducted and analysed applying the Taguchi method. It was found that the electrode wear rate reduces substantially as concluded [18]. The influence of pinholes on the chip on film (COF) in screen-printing was studied. The process parameters such as ink capacity, origin control distance, angle of the squeezer, method of mixing, freshness of ink, speed of printing, and speed of scraper were considered to improve the pinholes as studied [19]. The influence of the cutting parameters, such as cutting speed, feed rate and point angle on delamination produced during drilling a GFRP composite was studied. The point angle of $118^{\circ}$ drill produced less damage on the entrance of GFRP composite than the point angle of $135^{\circ}$ drill as observed [20]. The optimization of injection molding process for friction properties of fiber-reinforced polybutylene terephthalate was done using taguchi method and principal component analysis [21]. The combined quality function deployment (QFD) and the taguchi method to analyze the produced quality characteristics and to optimize the process parameters was applied [22]. The $\mathrm{CO}_{2}$ continuous laser welding process was successfully applied and optimized for joining a dissimilar AISI 316 stainless-steel and AISI 1009 low carbon steel plates [23]. The use of an Nd:YAG laser for thin plate magnesium alloy butt welding was optimized using the taguchi analytical methodology. The optimal result was confirmed with a superior ultimate tension stress of $169 \mathrm{MPa}, 2.5$ times larger to that from original set for laser welding as determined [24]. An experimental investigation into the effects of cutting speed, feed rate, depth of cut, nose radius and cutting environment in CNC turning of AISI P-20 tool steel was done. Design of experiment techniques, i.e. response surface methodology (RSM) and Taguchi's technique was used to accomplish the objective of the experimental study [25].

\section{Materials and Method}

Taguchi's method of experimental design provides a simple, efficient and systematic approach to determine optimal machining parameters as studied [26]. Taguchi has recommended orthogonal arrays (OA) for the designing of experiments. In taguchi method, the results of experiments are analyzed to achieve one or more of the objectives as to establish the best or the optimum condition for a product or process. Analysis of variance (ANOVA) is the statistical treatment applied to the results of the experiments in determining the percent contribution of each parameter against a stated level of confidence. The study of ANOVA table for a given analysis helps to determine which of the parameters need control and which do not .Taguchi suggested two different routes to carry out the complete analysis. First, the standard approach; where the results of a single run or the average of repetitive runs are processed through main effect and analysis of variance. The second approach, which taguchi strongly recommends for multiple runs, is to use signal-to-noise (S/N) ratio for the same steps in the analysis. The $\mathrm{S} / \mathrm{N}$ ratio is a concurrent quality metric linked to the loss function as reported [27]. Design of experiment (DOE) methods results in an efficient experimental schedule and produce a statistical analysis to determine easily as to which parameters have the most significant effects on the final results. The use of signal-to-noise $(\mathrm{S} / \mathrm{N})$ ratio in system analysis provides a quantitative value for response variation comparison. The requirement to test multiple factors means that a full factorial experimental design that describes all possible conditions would result in a large number of experiments. There are several $\mathrm{S} / \mathrm{N}$ ratios available depending on the types of characteristics; lower is better (LB), nominal is best (NB), and higher is better (HB).

Lower-the-better type problem.

$$
\eta=-10 \log _{10}\left(1 / n \sum_{i=1}^{n} y_{i}^{2}\right)
$$

where $(\mathrm{S} / \mathrm{N})$ is the inspection index, defined as the signal-to-noise ratio (unit: $\mathrm{dB}$ ), $\mathrm{n}$ is the number of repetitions for each trial, independent of the values assigned to noise factors, and $y_{i}$ is the value of the response obtained in the $\mathrm{i}^{\text {th }}$ repetition of the trial.

Higher-the-better type problem.

In this type of problem, the quality characteristic is again continuous and non-negative and it is to be made as large as possible. There is no adjustment factor to be used in this case as well and one is interested in maximizing the objective function expressed as:

$$
\eta=-10 \log \left\{\frac{1}{n} \cdot \sum_{1}^{n} \frac{1}{y_{i}^{2}}\right\}
$$


Nominal-the-best type problem.

In the nominal-the-best type problem, the quality characteristic is continuous and non-negative, but its target value is non zero and assumes some finite value. For these types of problems, if the mean becomes zero the variance also tends to become zero. A scaling factor can be used as an adjustment factor to shift the mean closer to the target for such type of problems. The objective function that is to be maximized can be expressed as:

$$
\begin{gathered}
\eta=10 \log _{10}\left(\mu^{2} / \sigma^{2}\right) \\
\mu=\frac{1}{n} \cdot \sum_{1}^{n} y_{i}^{2} \\
\sigma=\frac{1}{(n-1) \cdot \sum_{1}^{n}\left(y_{i}-\mu\right)^{2}}
\end{gathered}
$$

\section{Results and Discussion}

\subsection{Finite Element Modelling}

For the experimental cutting tool tuned to the longitudinal mode of vibration at $30 \mathrm{kHz}$ frequency, material Alloy Steel (High Carbon High Chromium Alloy Steel) and work-piece Glass. An increase in gain would allow a large range of amplitude to be investigated. To increase the vibration amplitude of the tool and for simplicity for tuning and comparison studies two symmetric circular cuts were taken from both uniform rod along the longitudinal axis to reduce the cross sectional area from the base to the tip, as shown in Figure 1.

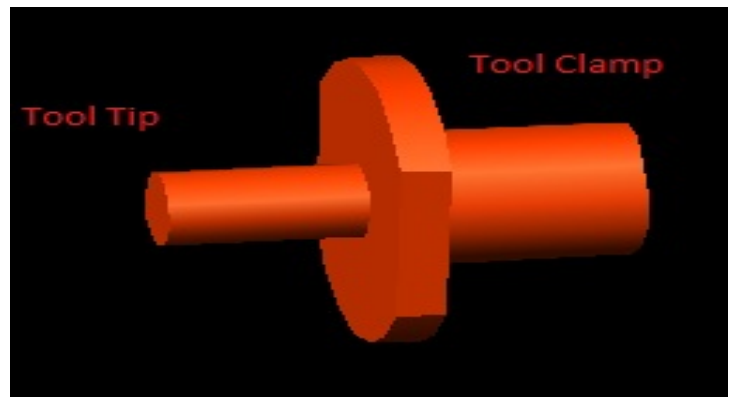

Figure 1. Symmetric circular cuts through a uniform rod

\subsubsection{Boundary Conditions and Loads}

Boundary conditions are the conditions existing at the physical boundary of the domain. In stress analysis problem they refer to displacements or rotation and forces/ moment conditions. Since the upper part of the ultrasonic tool is fixed in the horn therefore no longitudinal movements and no rotational movements are allowed. The boundary conditions were imposed to finite element model by freezing all degrees of freedom of motion at one end (ENCASTRE; U1=U2=U3=UR1=UR2=UR3=0). The same condition was applied to the work piece which was holded at the base. The load applied on the tip of the ultrasonic tool is $100 \mathrm{~N} / \mathrm{m}^{2}$ in the longitudinal direction direct to the work piece. During machining operation pressure is also applied on the sides wall of the ultrasonic tool that is approximately half the force applied on the tip i.e. $50 \mathrm{~N} / \mathrm{m}^{2}$. This happens because the abrasive particles get stuck in the gap between tool and work piece hole and due to this effect the hole diameter generated is always bigger than the required hole diameter. The force is transferred to the abrasive and these abrasives strike with the work piece to remove the material by erosion effect. These are 6586 tetrahedral elements were generated for the studies to ultrasonic tool and 12858 tetrahedral elements were generated for the studies to the glass workpiece. In which 21 tetrahedral elements are come on the surface of the tip of USM tool. The maximum stresses are generated in this part.

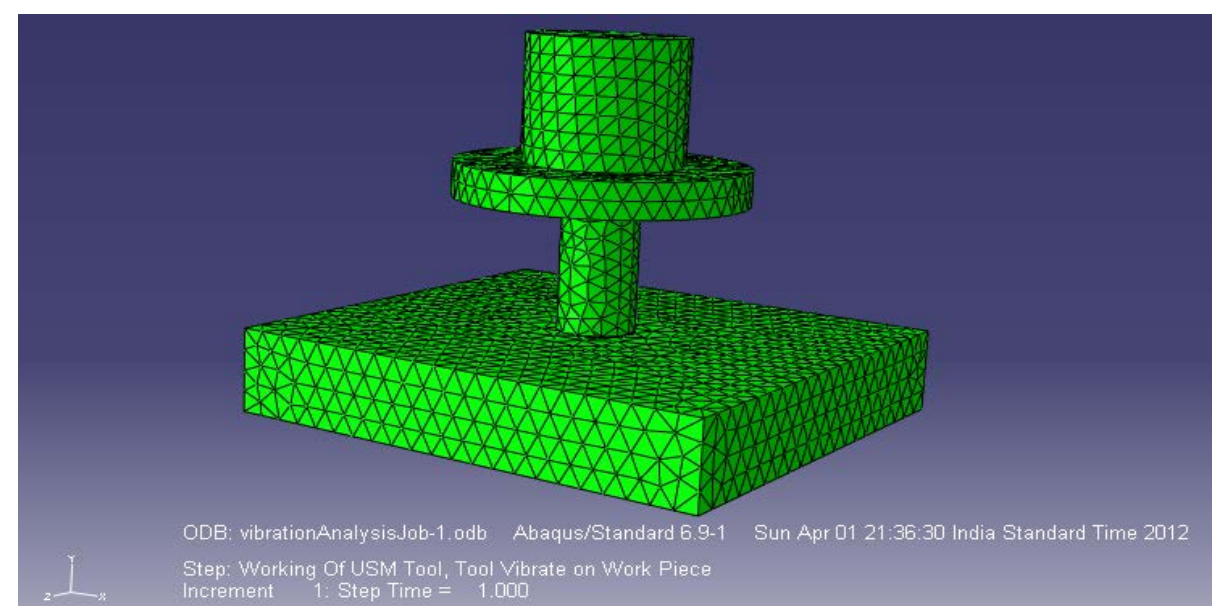

Figure 2. Modal in ABAQUS with boundary condition

The orthogonal array based on the taguchi concept was utilized to arrange the discrete variables and robust solutions for unconstrained optimization problems were found. In this investigation, the four machining parameters, abrasive slurry, slurry concentration, grit size and power rating were taken. The two levels of slurry concentration and others each of three different levels were taken.
According to taguchi, the samples could be organized into only 18 groups and if they were to be considered separately still it yield results with the same confidence. The $\mathrm{S} / \mathrm{N}$ ratios of surface roughness in single quality optimization according to the arrangement of the samples into 18 groups; $\mathrm{L}_{18}$ according to taguchi is shown in Table 1. 
Table 1. Results of surface roughness

\begin{tabular}{|c|c|c|c|c|c|c|c|}
\hline Trail No: & $\begin{array}{c}\text { Slurry } \\
\text { Concentration }\end{array}$ & Abrasive & $\begin{array}{c}\text { Power Rate } \\
(\%)\end{array}$ & Grit Size & $\begin{array}{c}\text { SR } \\
(\mu \mathrm{m})\end{array}$ & S/N Ratio & Mean \\
\hline 1 & 20 & $\mathrm{Al}_{2} \mathrm{O}_{3}$ & 20 & 280 & 0.55 & 5.19275 & 0.55 \\
\hline 2 & 20 & $\mathrm{Al}_{2} \mathrm{O}_{3}$ & 40 & 400 & 0.70 & 3.09804 & 0.70 \\
\hline 3 & 20 & $\mathrm{Al}_{2} \mathrm{O}_{3}$ & 60 & 600 & 1.08 & -0.66848 & 1.08 \\
\hline 4 & 20 & $\mathrm{SiC}$ & 20 & 280 & 1.15 & -1.21396 & 1.15 \\
\hline 5 & 20 & $\mathrm{SiC}$ & 40 & 400 & 1.24 & -1.86843 & 1.24 \\
\hline 6 & 20 & $\mathrm{SiC}$ & 60 & 600 & 1.52 & -3.63687 & 1.52 \\
\hline 7 & 20 & Mixture & 20 & 400 & 0.99 & 0.08730 & 0.99 \\
\hline 8 & 20 & Mixture & 40 & 600 & 1.41 & -2.98438 & 1.41 \\
\hline 9 & 20 & Mixture & 60 & 280 & 1.09 & -0.74853 & 1.09 \\
\hline 10 & 30 & $\mathrm{Al}_{2} \mathrm{O}_{3}$ & 20 & 600 & 0.98 & 0.17548 & 0.98 \\
\hline 11 & 30 & $\mathrm{Al}_{2} \mathrm{O}_{3}$ & 40 & 280 & 1.02 & -0.17200 & 1.02 \\
\hline 12 & 30 & $\mathrm{Al}_{2} \mathrm{O}_{3}$ & 60 & 400 & 1.01 & -0.08643 & 1.01 \\
\hline 13 & 30 & $\mathrm{SiC}$ & 20 & 400 & 1.24 & -1.86843 & 1.24 \\
\hline 14 & 30 & $\mathrm{SiC}$ & 40 & 600 & 1.63 & -4.24375 & 1.63 \\
\hline 15 & 30 & $\mathrm{SiC}$ & 60 & 280 & 1.48 & -3.40523 & 1.48 \\
\hline 16 & 30 & Mixture & 20 & 600 & 1.49 & -3.46373 & 1.49 \\
\hline 17 & 30 & Mixture & 40 & 280 & 1.30 & -2.27887 & 1.30 \\
\hline 18 & 30 & Mixture & 60 & 400 & 1.62 & -4.19030 & 1.62 \\
\hline
\end{tabular}

The knowledge of the contribution of individual factors is critically important for the control of the final response. The parameters sum of squares (SS), pure sum of squares (SS), degree of freedom (DOF), Mean sum of squares (MS), F-ratio, P-value and percentage of each factor were calculated.

The Sum of Squares (SS) is a measure of the deviation of the experimental data from the mean value of the data. Let ' $A$ ' be a factor under investigation.

$$
S S_{T}=\sum_{i=1}^{N}\left(y_{i}-T\right)^{2}
$$

Where $\mathrm{N}=$ Number of response observations, $\mathrm{T}$ is the mean of all observations $y_{i}$ is the $i^{\text {th }}$ response.

Factor Sum of Squares $\left(\mathrm{SS}_{\mathrm{A}}\right)$ - Squared deviations of factor (A) averages from overall average.

$$
S S_{A}=\left[\sum_{i=1}^{k_{a}}\left(\frac{A_{i}^{2}}{n_{A i}}\right)\right]-T^{2} / N
$$

Average of all observations under $\mathrm{A}_{\mathrm{i}}$ level $=\mathrm{A}_{\mathrm{i}} / \mathrm{n}_{\mathrm{Ai}}, T=$ sum of all observations, $\mathrm{n}_{\mathrm{Ai}}=$ Number of observation under $\mathrm{A}_{\mathrm{i}}$ level.

Error Sum of Squares $\left(S S_{e}\right)$ - Squared deviations of observations from factor (A) averages.

$$
S S_{e}=\sum_{j=1}^{k_{A}} \sum_{i=1}^{n_{A i}}\left(y_{i}-A_{j}\right)^{2}
$$

Sum of Squares $\left(S S_{A x B}\right)$ for interactions.

$$
\left.S S_{A x B}=\left[\sum_{i=1}^{c}(A x B)_{i}^{2} / n_{(A x B) i}\right)\right]-T^{2} / N-S S_{A}-S S_{B}
$$

\subsection{Analysis of Variance for Surface Roughness}

The results of surface roughness wwre analyzed using ANOVA for identifying the significant factor affecting the performance measure. The analysis of variance (ANOVA) for the mean surface roughness at $95 \%$ confidence interval is given in Table 2 .

The P-value determines that if the P-value is less than 0.05 that factors or interactions are significant. From the ANOVA Table 2 it was observed that the $\mathrm{P}$ values for slurry concentration, type of abrasive, power rating and grit size are $0.002,0.001,0.005$ and 0.003 respectively. All these factors are significant but as the p-value for the

\begin{tabular}{|c|c|c|c|c|c|c|c|c|}
\hline Source & DOF & Seq SS & Adj MS & $\mathrm{F}$ & $\mathrm{P}$ & SS' & \% Contribution & Status \\
\hline Concentration,A & 1 & 0.2312 & 0.23120 & 30.54 & 0.002 & 0.2238 & 14.4813 & Significant \\
\hline Abrasive, $\mathrm{B}$ & 2 & 0.8449 & 0.42248 & 55.80 & 0.001 & 0.8302 & 53.7193 & Significant \\
\hline Power Rate, C & 2 & 0.1677 & 0.08388 & 11.08 & 0.005 & 0.1530 & 9.9001 & Significant \\
\hline Grit Size, D & 2 & 0.2261 & 0.10465 & 13.82 & 0.003 & 0.2114 & 13.6790 & Significant \\
\hline $\mathrm{A} \times \mathrm{C}$ & 2 & 0.0147 & 0.00738 & 0.98 & 0.418 & -0.002 & --- & Insignificant \\
\hline Residual Error & 8 & 0.0605 & 0.00757 & -- & -- & -- & --- & --- \\
\hline Total & 17 & 1.5454 & -- & -- & -- & -- & --- & --- \\
\hline e-Pooled & 10 & 0.0753 & 0.0075 & -- & -- & -- & 8.2203 & --- \\
\hline
\end{tabular}
interaction between slurry concentration and Power rating is more than 0.05 , it is insignificant. The Table 3 presents the ranks for the process parameters.

Table 3. Response table for means of surface roughness

\begin{tabular}{|c|c|c|c|c|}
\hline Level & Concentration & Abrasive & Power Rate & Grit Size \\
\hline 1 & 1.0811 & 0.8900 & 1.0667 & 1.0983 \\
\hline 2 & 1.3078 & 1.3767 & 1.2167 & 1.3000 \\
\hline 3 & -- & 1.3167 & 0.2333 & 3 \\
\hline Delta & 0.2267 & 0.4867 & 1.3517 & 0.2533 \\
\hline Rank & 4 & 1 & 2 \\
\hline
\end{tabular}

The ascending order of ranks is given as grit size, type of abrasive, power rating and slurry concentration. The type of abrasive is most significant parameter and slurry concentration is the least significant parameter and having minimum contribution to the surface roughness. From Fig 3 , it was observed that the surface roughness is less using $\mathrm{Al}_{2} \mathrm{O}_{3}$ as compared to using mixture (aluminium oxide + silicon carbide) of abrasive slurry. 


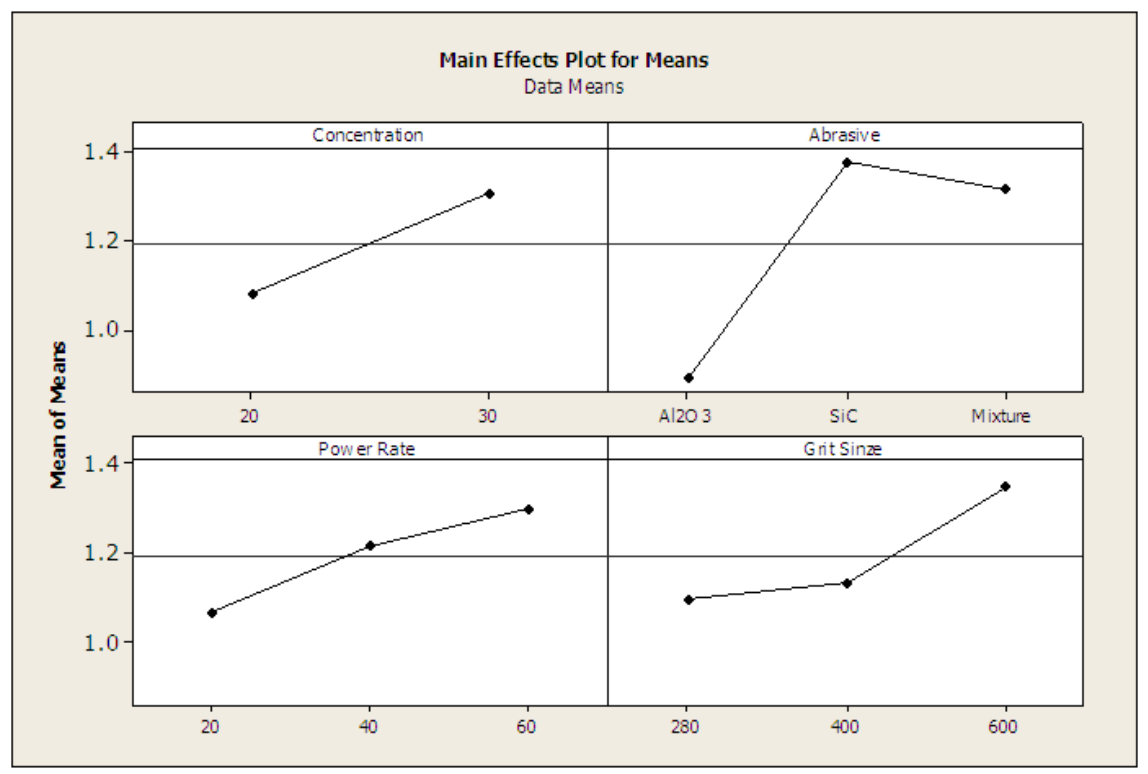

Figure 3. Main effects plot of surface roughness for means

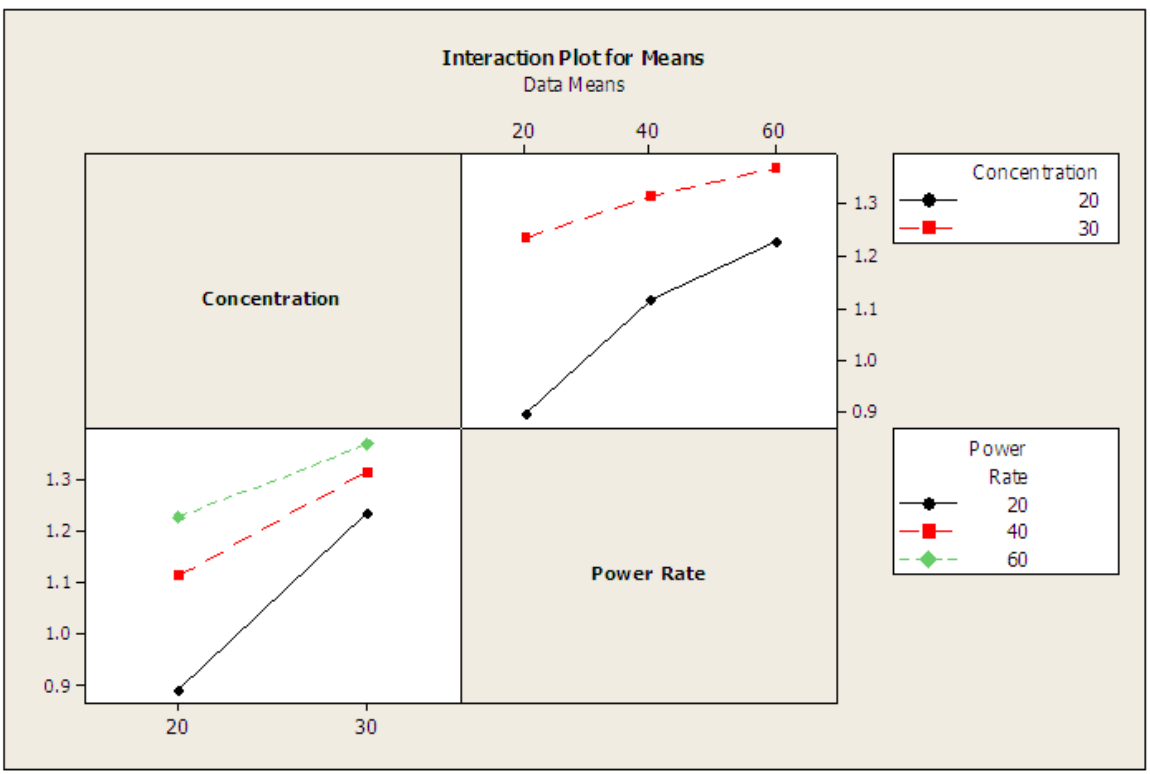

Figure 4. Interaction plot for surface roughness

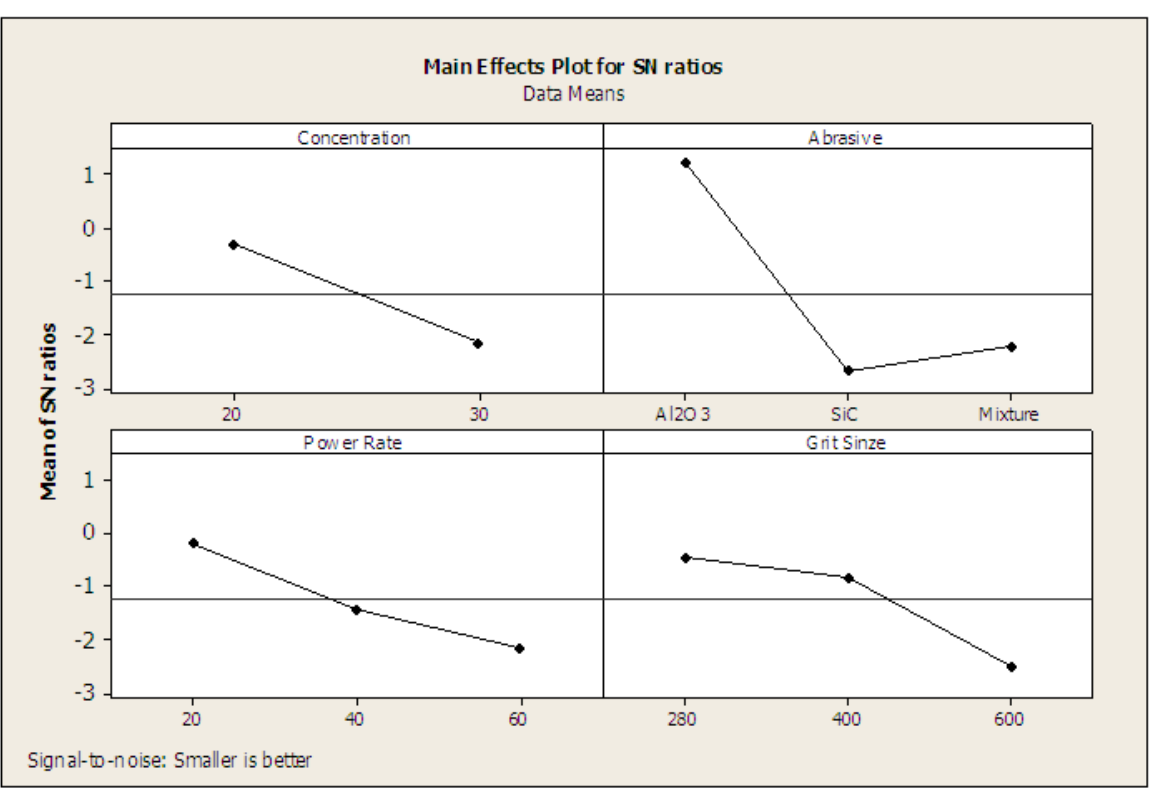

Figure 5. Main effects plot of surface roughness for $\mathrm{S} / \mathrm{N}$ ratio 


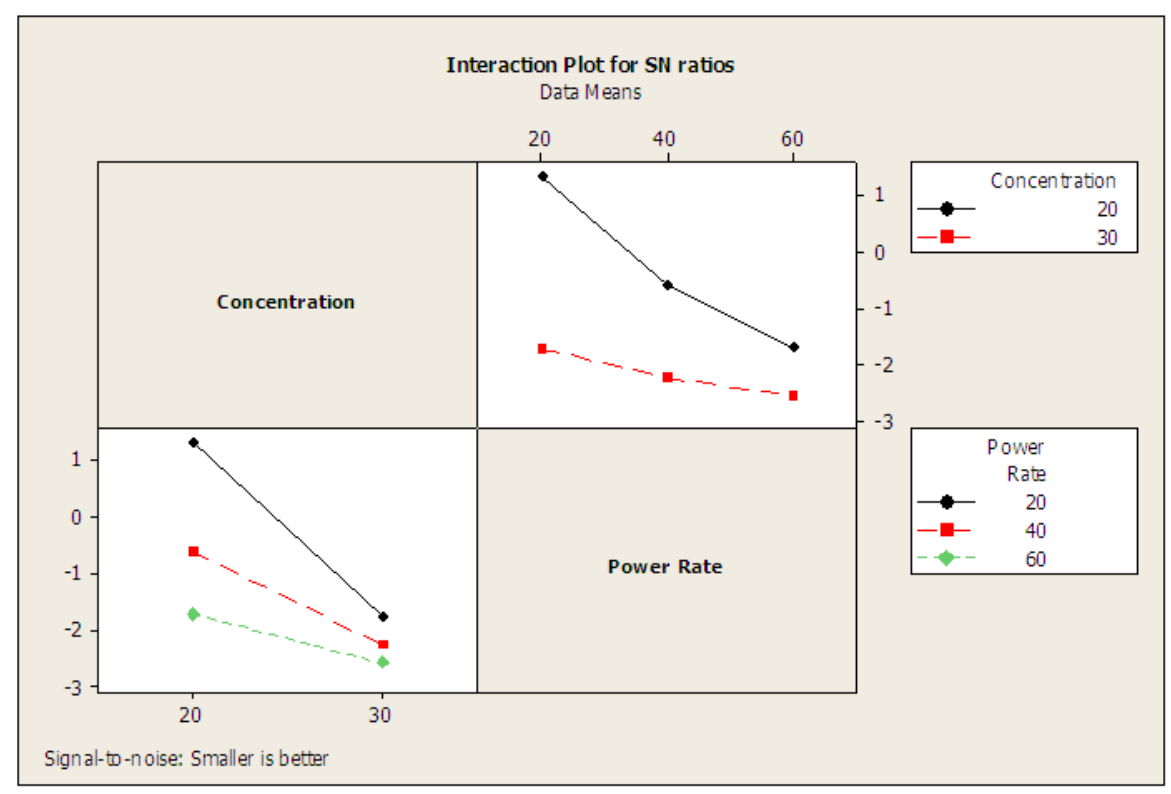

Figure 6. Interaction plot for surface roughness of $\mathrm{S} / \mathrm{N}$ ratio

Table 4 presents the ANOVA results for $\mathrm{S} / \mathrm{N}$ ratio of surface roughness at $95 \%$ confidence interval.

\begin{tabular}{|c|c|c|c|c|c|c|c|c|}
\multicolumn{10}{c|}{ Table 4. ANOVA for S/N Ratio of surface roughness } \\
\hline Source & DOF & Seq SS & Adj MS & F & P & SS, & \% Contribution & Status \\
\hline Concentration,A & 1 & 15.663 & 15.6626 & 17.75 & 0.003 & 14.7808 & 14.0741 & Significant \\
\hline Abrasive, B & 2 & 56.574 & 28.2870 & 32.06 & 0.001 & 54.8096 & 52.1892 & Significant \\
\hline Power Rate, C & 2 & 11.563 & 5.7816 & 6.55 & 0.021 & 9.7986 & 9.3301 & Significant \\
\hline Grit Size, D & 2 & 14.081 & 5.2158 & 5.91 & 0.027 & 12.3166 & 11.7277 & Significant \\
\hline A x C & 2 & 0.083 & 0.0413 & 0.05 & 0.955 & -1.346 & --- & Insignificant \\
\hline Residual Error & 8 & 7.058 & 0.8822 & -- & -- & -- & --- & -- \\
\hline Total & 17 & 105.021 & -- & -- & -- & -- & --- & -- \\
\hline e-Pooled & 10 & 7.1410 & 0.7141 & -- & -- & -- & 12.6789 & -- \\
\hline
\end{tabular}

From the ANOVA Table 4 it was observed that the $\mathrm{P}$ values for slurry concentration, type of abrasive, power rating and grit size are $0.010,0.002,0.038$ and 0.000 respectively. All these factors are significant but as the p- value for the interaction between slurry concentration and Power rating is more than 0.05 , it is insignificant. The Table 5 presents the ranks for the process parameters.

Table 5. Response table for $\mathrm{S} / \mathrm{N}$ ratio of surface roughness

\begin{tabular}{|c|c|c|c|c|}
\hline Level & Concentration & Abrasive & Power Rate & Grit Size \\
\hline 1 & -0.3047 & 1.2566 & -0.1818 & -0.4376 \\
\hline 2 & -2.1704 & -2.7061 & -1.4082 & -0.8047 \\
\hline 3 & -- & -2.2631 & -2.1226 & -2.4703 \\
\hline Delta & 1.8656 & 3.9627 & 1.9409 & 2.0326 \\
\hline Rank & 4 & 1 & 3 & 2 \\
\hline
\end{tabular}

Table 6. Significant factor and interaction

\begin{tabular}{|c|c|c|c|c|}
\hline \multirow{2}{*}{ Factor } & \multicolumn{2}{|c|}{ Affecting Mean } & \multicolumn{2}{|c|}{ Affecting Variation } \\
\hline & Contribution & Best Level & Contribution & Best Level \\
\hline Concentration, $\mathrm{A}$ & Significant & Level-2(30\%) & Significant & Level-1(20\%) \\
\hline Abrasive, B & Significant & Level-2 (SiO) & Significant & Level-1 $\left(\mathrm{Al}_{2} \mathrm{O}_{3}\right)$ \\
\hline Power Rate, C & Significant & Level-3(60) & Significant & Level-1(20) \\
\hline Grit Size, D & Significant & Level-3 (600) & Significant & Level-1(280) \\
\hline $\mathrm{A} \times \mathrm{C}$ & Insignificant & --- & Insignificant & --- \\
\hline
\end{tabular}

\subsubsection{Confidence Interval Around the Estimated Mean for Surface Roughness}

Mean Value for surface roughness $\mu \mathrm{A}_{2} \mathrm{~B}_{2} \mathrm{C}_{3} \mathrm{D}_{3}=\mathrm{A}_{2}+$ $\mathrm{B}_{2}+\mathrm{C}_{3}+\mathrm{D}_{3}-3 \mathrm{~T}=1.3078+1.3767+1.3000+1.3517-3$ $\mathrm{x} 1.333=1.3422$ micron.

The confidence interval is a maximum and minimum value between which the true average should fall at some stated percentage of confidence. The estimate of the mean $\mu$ is only a point estimate based on the averages of results obtained from the experiment. Statistically this provides a $50 \%$ chance of the true averages being greater than $\mu$ and a $50 \%$ chance of the true average being less than $\mu$.
Confidence Interval around the estimated surface orughness mean.

$$
C I_{1}=\sqrt{\left(F_{\alpha, V_{1}, V_{2}} V_{e}\right) / n_{e f f}}
$$

Where $F \alpha V_{1} V_{2}=F$ ratio, $\alpha=$ Risk (0.01) Confidence $=1-\alpha, V_{1}=\mathrm{DOF}$ for mean which is always $=1, \mathrm{~V}_{2}=$ DOF for error $=V e, \eta_{\text {eff }}=$ Number of tests under that condition using the participating factors.

$$
\begin{gathered}
\eta_{\text {eff }}=\left(\mathrm{N} / 1+\mathrm{DOFA}_{2} \mathrm{~B}_{2} \mathrm{C}_{3} \mathrm{D}_{3}\right)=18 / 1+1+2+2+2=2.25 \\
C I_{1}=\sqrt{(4.561 X 0.0075) / 2.25}=0.082
\end{gathered}
$$

So the confidence interval around the surface roughness is given by $1.3422 \pm 0.082$ micron. 


\section{References}

[1] Tosun, N., "Determination of optimum parameters for multiperformance characteristics in drilling by using grey relational analysis”, International Journal of Advanced Manufacturing Technology. 28. 450-455. 2006.

[2] Chang, C.K., Lu, H.S., "Design optimization of cutting parameters for side milling operations with multiple performance characteristics”, International Journal of Advanced Manufacturing Technology, 32. 18-26. 2007.

[3] Kumar, V., Khamba, S., "Statistical analysis of experimental parameters in ultrasonic machining of tungsten carbide using taguchi approach”, Journal of American Ceramic Society. 91. 9296. 2008.

[4] Kopac, J., Krajnik, P., "Robust design of flank milling parameters based on grey-taguchi method", Journal of Materials Processing Technology. 191. 400-403. 2007.

[5] Xiansheng, N., Zhenggan, Z., Xiongwei, W., Luming, L., “The use of taguchi method to optimize the laser welding of sealing neuro-stimulator", Optics and Lasers in Engineering. 49. 297-304. 2011.

[6] Lin, Y.C., Chen, Y.F., Wang, D.A., Lee, H.S., “ Optimization of machining parameters in magnetic force assisted EDM based on taguchi method”, Journal of Materials Processing Technology 209. 3374-3383. 2009.

[7] Liu, Y.T., Chang, W.C., Yamagata, Y., “A study on optimal compensation cutting for an aspheric surface using the taguchi method",CIRP Journal of Manufacturing Science and Technology. 3. 40-48. 2010.

[8] Comakli, K., Simsek, F.,Comakli, O., Sahin, B., "Determination of optimum working conditions R22 and R404A refrigerant mixtures in heat-pumps using taguchi method", Applied Energy. 86. 2451-2458. 2009.

[9] Ming, L.J., Lu, P.L., Weng, W.K., "Modifications of ITO surfaces in OLED devices by taguchi methods", Materials Science and Engineering. 85. 209-211. 2001.

[10] Chang, C.W., Kuo, C.P., "Evaluation of surface roughness in laser-assisted machining of aluminum oxide ceramics with taguchi method", International Journal of Machine Tools \& Manufacture. 47. 141-147. 2007.

[11] Tosun, N., Cogun, C., Tosun, G., "A study on kerf and material removal rate in wire electrical discharge machining based on taguchi method”, Journal of Materials Processing Technology. 152. 316-322. 2004.

[12] Gologlu, C., Sakarya, N., "The effects of cutter path strategies on surface roughness of pocket milling of 1.2738 steel based on Taguchi method", Journal of Materials Processing Technology. 206. 7-15. 2008.

[13] Kapsiz, M., Durat, M., Ficici, F., “ Friction and wear studies between cylinder liner and piston ring pair using taguchi design method," Advances in Engineering Software. 42. 595-603. 2011.
[14] Rosa, J.L., Robin, A., Silva, M.B., Baldan, C.A., Peres, M.P., "Electro deposition of copper on titanium wires: taguchi experimental design approach”, Journal of Materials Processing Technology 209. 1181-1188. 2009.

[15] Thipprakmas, S., "Application of taguchi technique to investigation of geometry and position of V-ring indenter in fineblanking process," Materials and Design. 31.2496-2500. 2010.

[16] Savas, O., Kayikci, R., "Application of Taguchi's methods to investigate some factors affecting microporosity formation in A360 aluminium alloy casting”, Materials and Design 28. 22242228. 2007.

[17] Kishore, R.A., Tiwari, R., Dvivedi, A., Singh, I., "Taguchi analysis of the residual tensile strength after drilling in glass fiber reinforced epoxy composites”, Materials and Design. 30. 21862190. 2009.

[18] George, P.M., Raghunath, B.K., Manocha, L.M., Warrier, A.M., "EDM machining of carbon-carbon composite- A Taguchi approach", Journal of Materials Processing Technology. 145. 6671. 2004.

[19] Yen, Y.T., Fang, T.H., Lin, Y.C., “Optimization of screen-printing parameters of SN9000 ink for pinholes using taguchi method in chip on film packaging," Robotics and Computer-Integrated Manufacturing. 27. 531-537. 2011.

[20] Kilickap, E., "Optimization of cutting parameters on delamination based on taguchi method during drilling of GFRP composite ", Expert Systems with Applications. 37. 6116-6122. 2010.

[21] Fung, P.C., Kang, P.K., "Multi response optimization in friction properties of PBT composites using taguchi method and principle component analysis", Journal of Materials Processing Technology. 170. 602-610. 2005.

[22] Jeang, A., Chung, C.P., Chen, C.W., Li, H.C, “Optimizing process parameters of hot-bar soldering process through quality function deployment and taguchi method," Journal of Materials Processing Technology. 209. 2967-2977. 2009.

[23] Anawa, E.M., Olabi, A.G., "Using Taguchi method to optimize welding pool of dissimilar laser-welded components”, Optics \& Laser Technology, 40. 379-388. 2008.

[24] Pan, L.K., Wang, C.C., Hsiao, Y.C., Ho, K.C., "Optimization of Nd:YAG laser welding onto magnesium alloy via taguchi analysis", Optics \& Laser Technology. 37. 33-42. 2004.

[25] Aggarwal, A., Singh, H., Kumar, P., Singh, M., "Optimizing power consumption for CNC turned parts using response surface methodology and taguchi's technique-A comparative analysis", Journal of Materials Processing Technology, 200. 373-384. 2008.

[26] Phadke, M.S., Quality engineering using robust design. Prentice Hall, Englewood Cliffs, New Jersey. 1989.

[27] Roy ,R.K. “ A premier on the taguchi method, Van Nostrand Reinhold, New York. 1990. 